\title{
A simple method for the quantitative analysis of urinary trichloroethanol and trichloroacetic acid as an index of trichloroethylene exposure
}

\author{
MASANA OGATA, YOSHIKO TAKATSUKA, \\ and KATSUMARO TOMOKUNI (with technical assistance of KOZUE MUROI) \\ Department of Public Health, Okayama University Medical School, Okayama, Japan
}

\begin{abstract}
Ogata, M., Takatsuka, Y., and Tomokuni, K. (1970). Brit. J. industr. Med., 27, 378-381. A simple method for the quantitative analysis of urinary trichloroethanol and trichloroacetic acid as an index of trichloroethylene exposure. A simple method of estimating trichloroethanol and trichloroacetic acid in the urine of workers exposed to trichloroethylene is described. The glucuronide of trichloroethanol was hydrolysed enzymatically to trichloroethanol by $\beta$-glucuronidase and the trichloroethanol released was allowed to react with pyridine and potassium hydroxide in that order, thereby avoiding decomposition of trichloroethanol with strong alkali. The colour which developed in 3.5 minutes at $100^{\circ} \mathrm{C}$ with pyridine was measured at $440 \mathrm{~nm}$ and $530 \mathrm{~nm}$. This also allowed trichloroacetic acid to be determined. The results agreed well with those obtained by longer methods.
\end{abstract}

After a subject has been exposed to trichloroethylene, trichloroethanol and trichloroacetic acid are excreted in the urine (Butler, 1949) and this excretion has been correlated with the degree of exposure (Tanaka and Ikeda, 1968; Ogata and Tomokuni, 1969). As trichloroethanol and trichloroacetic acid excretion occur at different rates (Soucěk and Vlachová, 1960), and the excretion of the former is more closely related to exposure on the same day, whereas excretion of the latter is more closely related to exposure on a few previous days (Ogata and Tomokuni, 1969), both trichloroethanol and trichloroacetic acid must be estimated in the urine.

Previous methods required four hours' oxidation of trichloroethanol by chromium trioxide, and involved a difficult neutralization step before Fujiwara's colour reaction was carried out (Seto and Schultze, 1956; Weitbrecht, 1965; Tanaka and Ikeda, 1968).

We describe here a shorter method based on the work of Marshall and Owens (1954), who hydrolysed urinary trichloroethanol glucuronide enzymically before estimating trichloroethanol, and on the modification made by Friedman and Cooper (1958) of Fujiwara's reaction for trichloroethanol. They did not test the determination of urinary trichloroethanol in the form of glucuronide. The method described here allows the simultaneous estimation of trichloroethanol and trichloroacetic acid.

\section{Materials and methods}

Urine specimens were obtained from volunteers exposed for seven hours to $170 \mathrm{ppm}$ of trichloroethylene and from workers exposed for three hours to $50-150 \mathrm{ppm}$ of trichloroethylene at a motor car component factory.

\section{Analytical procedure}

To $1 \mathrm{ml}$ of urine were added $1 \mathrm{ml}$ of $0.15 \mathrm{M}$ phosphate buffer $(p \mathrm{H} \mathrm{6.0)}$ and $1 \mathrm{ml}$ of phosphate buffer containing 500 units (Fishman, Springer, and Brunetti, 1948) of $\beta$-glucuronidase (Sigma Chem. Co.), and the mixture was incubated at $37 \cdot 5^{\circ} \mathrm{C}$ for 40 or more minutes. A $1-\mathrm{ml}$ portion was taken and $5.0 \mathrm{ml}$ of pyridine was added, 
followed by $2.0 \mathrm{ml}$ of $10 \mathrm{M}$ potassium hydroxide. The mixture was agitated with a mechanical shaker, heated in a boiling water bath for exactly 3.5 minutes and immediately transferred to an ice bath for 3 to 5 minutes. Then $3 \mathrm{ml}$ of the pyridine layer was transferred to $0.5 \mathrm{ml}$ of water, and the mixture was diluted three times with pyridine/water (1/1). The optical densities of the solution at $440 \mathrm{~nm}$ and $530 \mathrm{~nm}$ were read immediately in a Beckman DU spectrophotometer. When a number of samples were to be determined, the solutions were kept in an ice bath until they were assayed. Standard solutions were obtained by using aqueous solutions of trichloroethanol and trichloroacetic acid instead of urine in the above method.

All analyses were carried out by an autorecording spectrophotometer (Beckman $\mathrm{DK}_{2}$ ).

As shown in Fig. 1, absorption at $440 \mathrm{~nm}$ was almost wholly due to trichloroethanol and that at $530 \mathrm{~nm}$ was almost entirely due to trichloroacetic acid.

The calculation of the results depends on the separation of the optical densities measured at 440 and $530 \mathrm{~nm}$, $U_{440}$ and $U_{530}$, into their component parts, $U_{440 E}$ etc., the optical densities (OD) due to each component at each wave length. Thus we define:

$\mathrm{U}_{440}=$ OD at $440 \mathrm{~nm}$ from urine

$U_{530}=O D$ at $530 \mathrm{~nm}$ from urine

$U_{440 E}$ and $U_{530 E}=O D$ in urine at 440 and $530 \mathrm{~nm}$ due to trichloroethanol

$U_{440 A}$ and $U_{530 A}=O D$ in urine at 440 and $530 \mathrm{~nm}$ due to trichloroacetic acid.

By definition:

$$
\begin{aligned}
& \mathbf{U}_{440}=\mathbf{U}_{440 \mathrm{E}}+\mathbf{U}_{440 \mathrm{~A}} \ldots \ldots \ldots \ldots \ldots \ldots \ldots \ldots \ldots \ldots \ldots \ldots \ldots \ldots \ldots \ldots \ldots \ldots \\
& \mathbf{U}_{530}=\mathbf{U}_{530 \mathrm{E}}+\mathbf{U}_{530 \mathrm{~A}} \ldots \ldots \ldots \ldots \ldots \ldots \ldots
\end{aligned}
$$

Experimentally, from Fig. 1:

$$
\begin{aligned}
\mathbf{U}_{530 \mathrm{E}} & =0.1 \mathbf{U}_{440 \mathrm{E}} \ldots \ldots \ldots \ldots \ldots \ldots \ldots \ldots \ldots \ldots \ldots \ldots \ldots \ldots \ldots \ldots \ldots \ldots
\end{aligned}
$$

Hence, substituting (4) in (1) and (3) in (2), we obtain the simultaneous equations:

$$
\begin{aligned}
& U_{440}=U_{440 \mathrm{E}}+0.06 U_{530 \mathrm{~A}} \\
& \mathrm{U}_{530}=0.1 \mathrm{U}_{440 \mathrm{E}}+\mathrm{U}_{530 \mathrm{~A}}
\end{aligned}
$$

Whence $U_{440 E}=\left(16.67 U_{440}-U_{530}\right) / 16.57 \ldots \ldots$

$U_{530 A}$ can be found by substituting the result from equation (7) in equation (6).

$$
\text { Then } \mathbf{C}_{\mathbf{E}}=\mathbf{U}_{440 \mathrm{E}} \times \mathrm{S}_{\mathrm{E}} / \mathbf{U}_{440 \mathrm{SE}} \ldots \ldots \ldots \ldots \text { (8), }
$$

where $C_{E}$ and $S_{E}$ are the concentrations of trichloroethanol in urine and in the aqueous standard, and $\mathrm{U}_{440 S E}$ is the OD given by the standard.

An exactly analogous equation:

$$
\mathrm{C}_{\mathrm{A}}=\mathrm{U}_{530 \mathrm{~A}} \times \mathrm{S}_{\mathrm{A}} / \mathrm{U}_{530 \mathrm{SA}}
$$

gives $C_{A}$ for trichloroacetic acid.

\section{Results}

The absorption spectra of the colours developed with pyridine from trichloroethanol and trichloro- acetic acid in urine are shown in Figure 1. The maxima for trichloroethanol were at $440 \mathrm{~nm}$ and $370 \mathrm{~nm}$ and those for trichloroacetic acid were at $530 \mathrm{~nm}$ and $370 \mathrm{~nm}$ respectively.

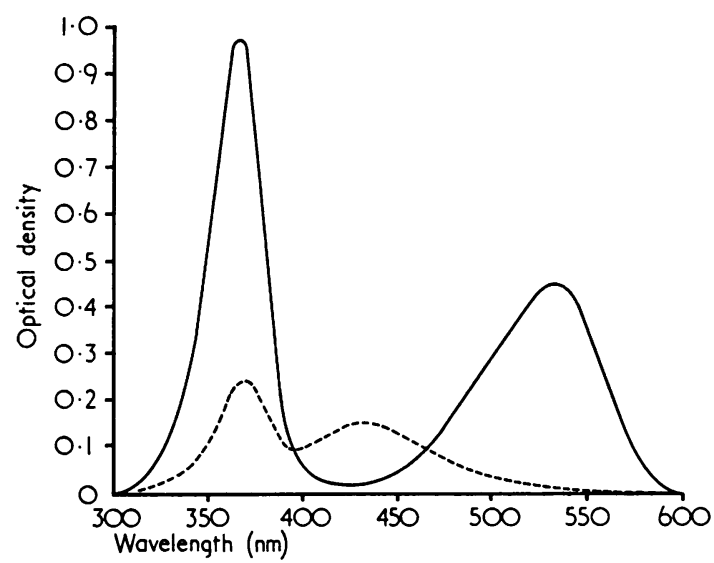

FIG. 1. Absorption spectra of the colours given by trichloroethanol and trichloracetic acid.

The percentage of the glucuronide of trichloroethanol hydrolysed by $\beta$-glucuronidase at $37.5^{\circ} \mathrm{C}$ is shown in Figure 2. The trichloroethanol released reached its maximum $\mathbf{4 0}$ minutes after incubation, apparently according to first order kinetics. Forty minutes was taken as sufficient time for the completion of enzymic hydrolysis. The same urines were analysed for trichloroethanol by the chromium trioxide oxidation method of Tanaka and Ikeda (1968). It was found that $97 \%$ of the trichloroethanol glucuronide was hydrolysed by the enzymic reaction, and that urinary trichloroacetic acid was stable in the procedure.

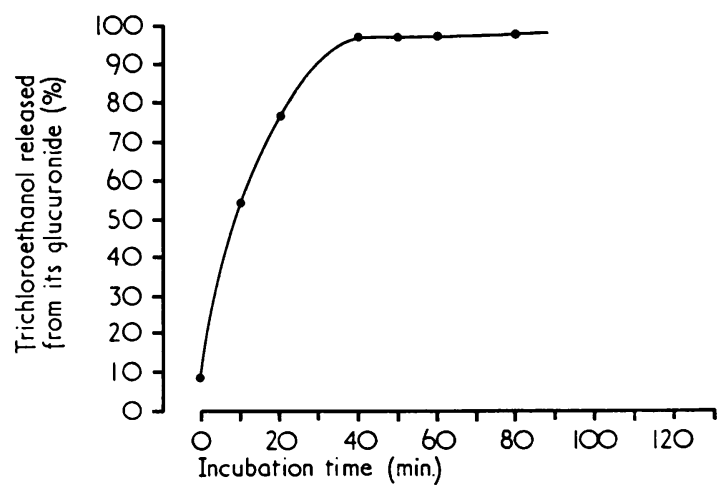

FIG. 2. Rate of hydrolysis of trichloroethanol glucuronide by $\beta$-glucuronidase at $37 \cdot 5^{\circ}$. 
A small amount of trichloroethanol was found in the urine before enzymatic hydrolysis, perhaps caused by some exposure to trichloroethylene. Monochloroacetic acid did not show a colour reaction under the conditions of the test.

Recoveries of trichloroethanol added to urine ranged from 90 to $102 \%$ and those of trichloroacetic acid from 93 to $96 \%$ (Table). The variations probably resulted from differences in the efficiencies of extraction and not from incomplete colour formation. In the case of trichloroethanol, hydrolysis of the glucuronide by $\beta$-glucuronidase was not negligible.

TABLE

ReCOVery of AdDED TRICHLOROETHANOL (TCE-OH) AND TRICHLOROACETIC ACID (TCA) FROM NORMAL URINE

\begin{tabular}{c|c}
\hline TCE-OH added $(\mu g)$ & Recovery $\%$ \\
\hline 50 & 90 \\
100 & 92 \\
150 & 102 \\
200 & 102 \\
\hline TCA added $(\mu g)$ & Recovery \% \\
\hline 50 & 95 \\
100 & 93 \\
150 & 95 \\
200 & 96 \\
\hline
\end{tabular}

A comparison was made of the concentrations of trichloroethanol and trichloroacetic acid found by the oxidation method (Tanaka and Ikeda, 1968) and by our method. Urine specimens were taken during and after exposure to trichloroethylene. The relationship between the values obtained by the two methods can be described by regression lines.

For trichloroethanol:

$$
\mathrm{y}_{1}=1.03 \mathrm{x}_{1}+0.53, \mathrm{r}=0.986
$$

where $x_{1}$ represents the values obtained by the oxidation method and $y_{1}$ those obtained by our direct colorimetric method (Fig. 3). There was good agreement between the results, though our method gave slightly higher values than the oxidation method.

For trichloroacetic acid:

$$
\mathrm{y}_{2}=1.08 \mathrm{x}_{2}-5.06, \mathrm{r}=0.996
$$

where $x_{2}$ represents the values obtained by the oxidation method and $y_{2}$ those obtained by our method (Fig. 4).

That the absorption at $440 \mathrm{~nm}$ was mostly due to trichloroethanol was shown by measuring the absorption spectrum of some specimens of urine

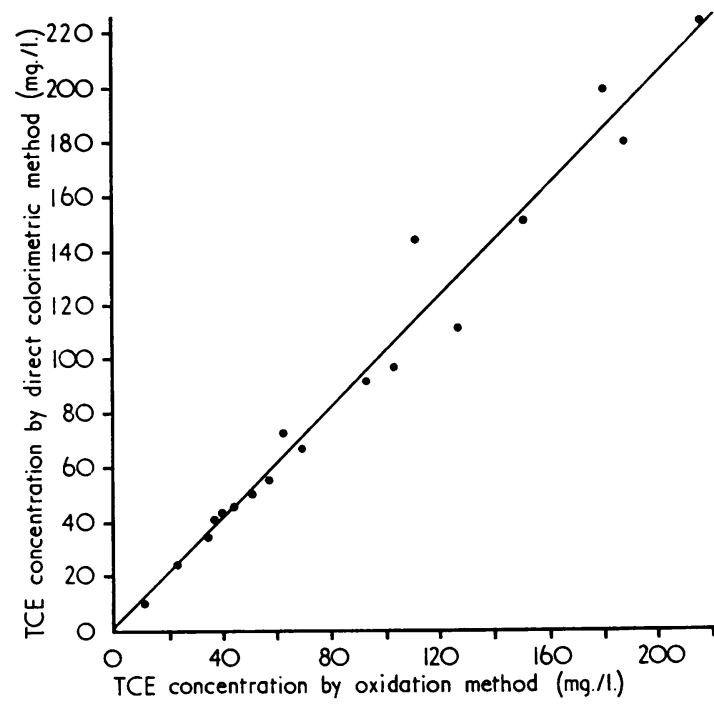

FIG. 3. Correlation between quantities of trichloroethanol estimated by the method of this paper and by the oxidation method.

obtained from a volunteer exposed to $170 \mathrm{ppm}$ of trichloroethylene for eight hours (Fig. 5). The large absorption peak at $\mathbf{4 4 0} \mathrm{nm}$ appeared after treatment with $\beta$-glucuronidase. There was also slightly increased absorption at $530 \mathrm{~nm}$, also due to the trichloroethanol released.

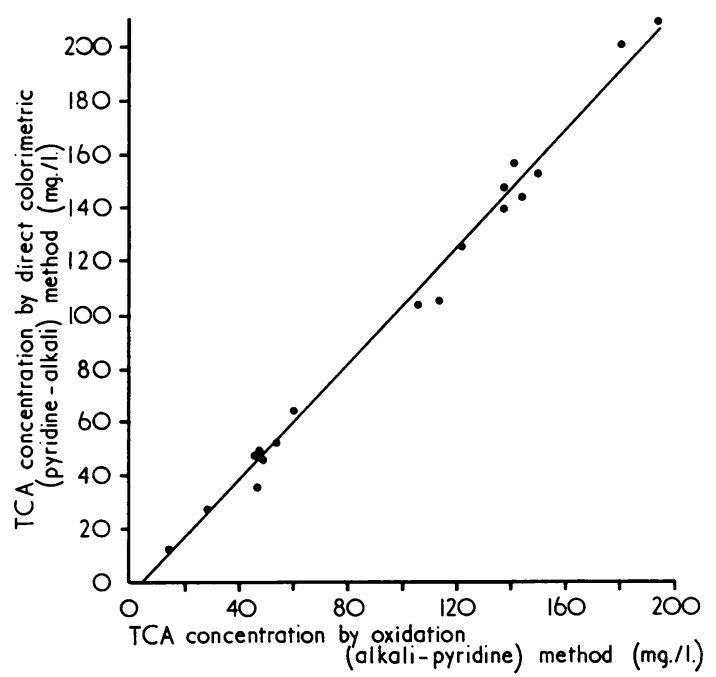

FIG. 4. Correlation between quantities of trichloroacetic acid estimated by the method of this paper and by the oxidation method. 


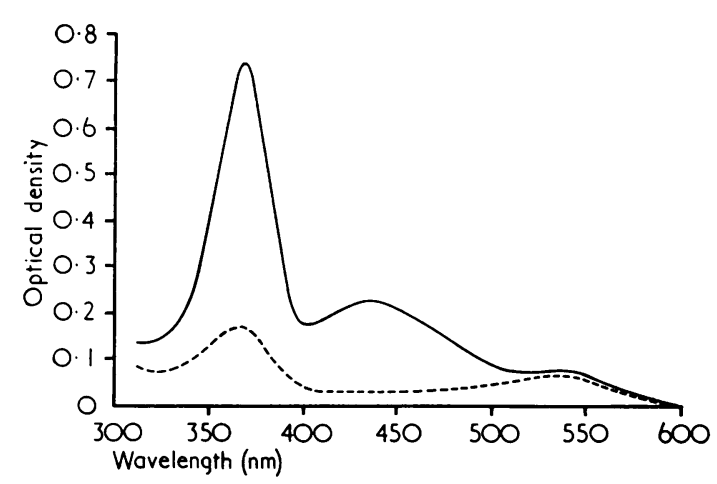

FIG. 5. Effects on the absorption spectra of treatment with $\beta$-glucuronidase of specimens of urine taken from a volunteer exposed to trichloroethylene. -__- before, after treatment.

\section{Discussion}

The quantitative determination of trichloroethanol and trichloroacetic acid in urine can be conducted very simply by the method described and the values obtained coincide with those obtained by the much longer oxidation method. Trichloroethanol was released from its glucuronide by $\beta$-glucuronidase. The quantitative determination of trichloroethanol by the Fujiwara reaction could not succeed because trichloroethanol is decomposed by strong alkali; but, by adding pyridine first, as described by Friedman and Cooper (1958), trichloroethanol was estimated successfully by a modified Fujiwara reaction. Friedman and Cooper (1958) attempted to measure chloral hydrate, trichloroacetic acid, and trichloroethanol simultaneously, this involving, therefore, a very complicated calculation. But, in urine excreted from workers exposed to trichloroethylene, only trichloroacetic acid and trichloroethanol were present, and their concentrations were easily calculated.

If the concentration of trichloroacetic acid is much lower than that of trichloroethanol, the former can be estimated by the pyridine-alkali method without prior treatment with $\beta$-glucuronidase.

\section{References}

Butler, T. C. (1949). Metabolic transformations of trichloroethylene. J. Pharmacol. exp. Ther., 97, 84-92.

Fishman, W. H., Springer, B., and Brunetti, R. (1948). Application of an improved glucuronidase assay method to the study of human blood $\beta$-glucuronidase. J. biol. Chem., 173, 449-456.

Friedman, P. J. and Cooper, J. R. (1958). Determination of chloral hydrate, trichloroacetic acid, and trichloroethanol. Anal. Chem. (Wash.), 30, 1674-1676.

Marshall, E. K. Jr., and Owens, A. H. (1954). Absorption, excretion and metabolic fate of chloral hydrate and trichloroethanol. Bull. Johns Hopk. Hosp., 95, 1-18.

Ogata, M. and Tomokuni, K. (1969). Excretion of toluene, xylene and tri- and tetra-chloroethylene metabolites in human urines as an index of exposure. Abstr 16th int. Congr. Occup. Hlth, 98.

Seto, T. A. and Schultze, M. O. (1956). Determination of trichloroethylene, trichloroacetic acid, and trichloroethanol in urine. Anal. Chem. (Wash.), 28, 1625-1629.

Souček, B. and Vlachová, D. (1960). Excretion of trichloroethylene metabolites in human urine. Brit. J. industr. Med., 17, 60-64.

Tanaka, S. and Ikeda, M. (1968). A method for determination of trichloroethanol and trichloroacetic acid in urine. Brit. J. industr. Med., 25, 214-219.

Weitbrecht, U. (1965). Tri und Tri-Ersatz in der Metallindustrie. Zbl. Arbeitsmed., 15, 138-146.

Received for publication January 5, 1970. 